Trade News is supplied as a service to the reader and does not imply endorsement by the BDJ. Normal and prudent research should be exercised before purchase or use of any product mentioned. Please send trade news information and illustrations to Sarah Murnal at the BDJ, 64 Wimpole Street, London WIM 8AL.

\section{Fair pay}

Rutherford Webb's new Internet-based payroll service - www.staffpay.net - promises to save dentists the worry of making incorrect payroll calculations and receiving possible penalties.

Surgery managers can use staffpay.net to calculate their employees' tax and national insurance, as well as their own employer's NI contributions. It offers a simple way to manage the complexities of the payroll and to comply with future legislation.

A free trial is available until the end of March 2000. Applications can be made via the company's web site, which also offers a free factsheet on all recent and pending legislation that affects the payrolls of all employers.

For confidentiality of payroll records, staffpay.net has been set up on a secure controlled web-server.

For further information visit the website or telephone 01813942515.

Reader response number:

051

\section{Give us a smile}

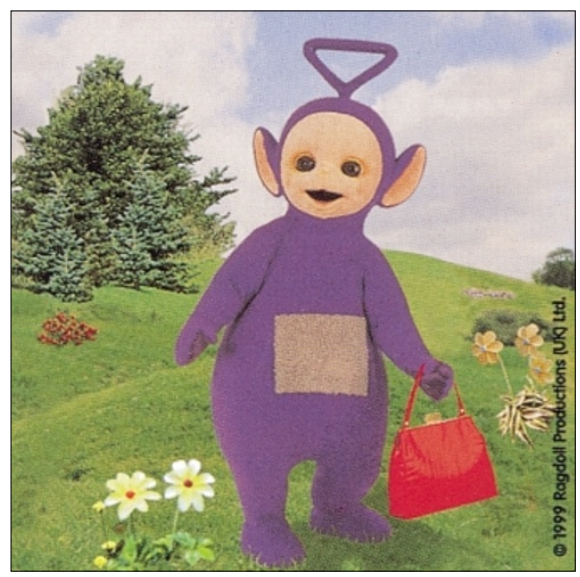

Smilemakers have introduced a range of Teletubbie stickers that is sure to be a hit with younger children. There are five different designs in total including all four characters from the popular TV series.

There is also an assortment of theme stickers including such classic characters as Barbie, Scooby Doo and Sesame Street. Rolls of stickers start from $\mathfrak{£} 3.75$.

Freephone 0800454806.

Reader response number:

\section{A whiter shade of pale}

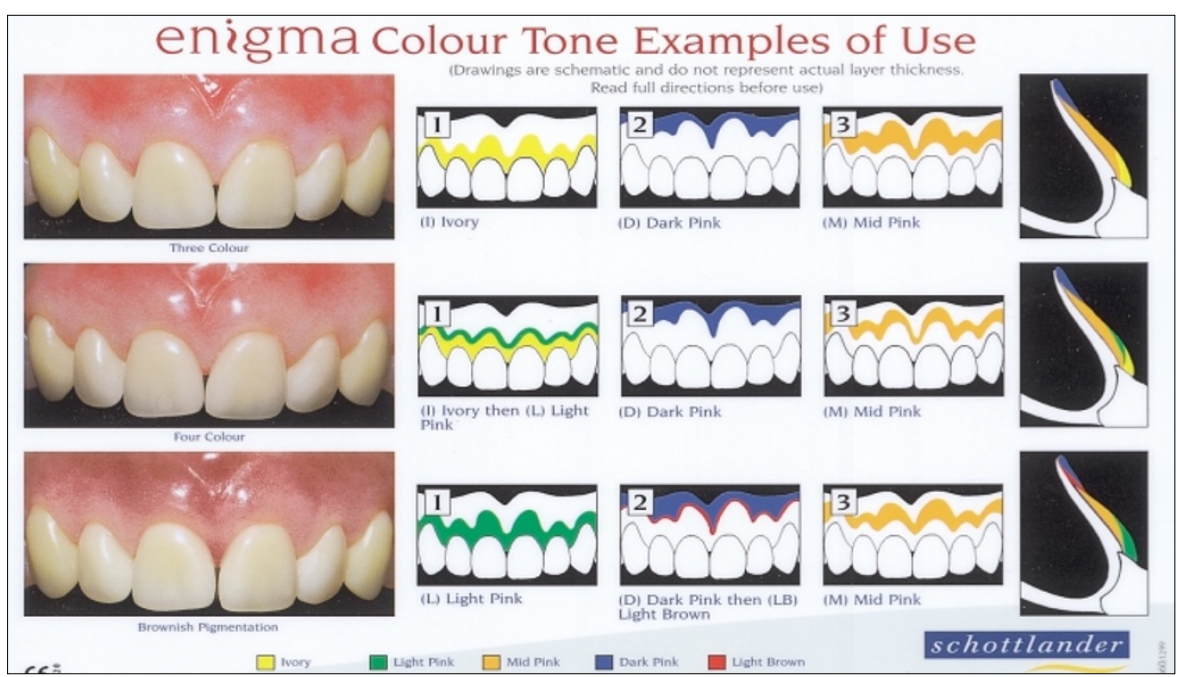

Schottlander announce the launch of Enigma Colour Tone. This new product is the result of extensive research over a number of years which has culminated in the long lasting coloration of acrylic gingival tissues, since the material's actual acrylic is layered within the denture itself.

The Enigma Colour Tone is applied in the flask using a similar technique to that employed for orthodontic resins. The powder is sifted into place using the powder dropper bottles, the monomer is added afterwards to stabilise the position.

There are seven colours in the Enigma Colour Tone ranging from ivory through to light pink and dark brown. Full directions for use are available including a pictoral card explaining the layering technique. A video also details the use of Enigma Colour Tone.

For further information, Freephone 0500234200 or Freefax 0500234400.

Reader response number:

\section{$\mathrm{Pb}$ wipes lead the way Disney does the trick}

The research team at Adelda Health have looked at how lead foils from dental $\mathrm{x}$-rays are being handled, and using this data, have created $\mathrm{Pb}$ Wipes.

The team claim that the use of $\mathrm{Pb}$ Wipes considerably reduces the risk of exposure to lead. The wipes are impregnated with a safe formulation of chemicals to eradicate lead foil dust from all surfaces, and are safe to use on all dental instruments.

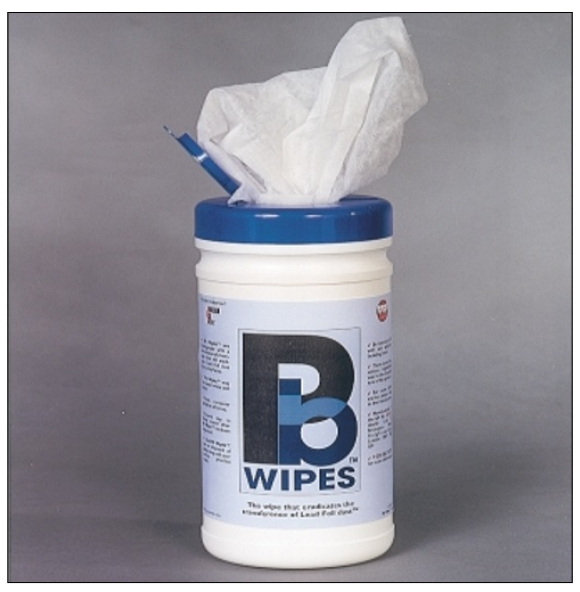

The wipes are priced at $\mathfrak{E} 7.99$ a tub and are available through Henry Schein Procare.

Call 02085370377 for information.

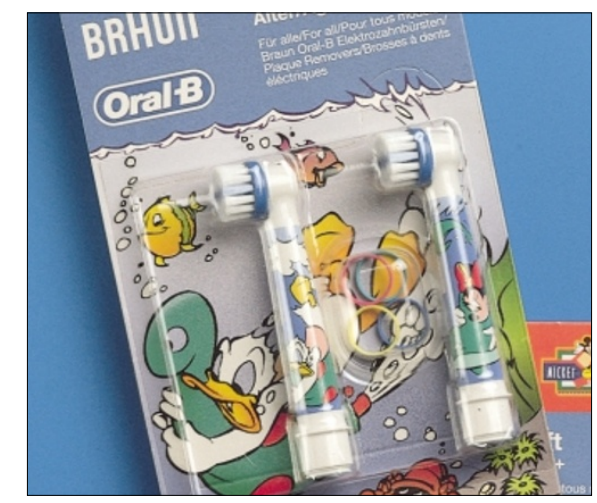

Braun Oral-B has produced a new children's brush head that can be used with any of its best-selling range of plaque removers. The colourful brushes carry various Disney designs featuring four of its popular characters - Mickey, Minnie, Pluto and Donald.

The extra-soft filaments on the head have 'flowered' ends to be gentle on children's teeth and gums. They also have substantially shorter filaments allowing better access and manoeuvrability in smaller mouths, whilst a raised horizontal row of filaments running across the centre of the brush give improved occlusal cleaning.

The brush heads are sold in twin-packs and cost the same as standard replacement heads. For more information call 01814042306.

Reader response number: 
Trade News is supplied as a service to the reader and does not imply endorsement by the BDJ. Normal and prudent research should be exercised before purchase or use of any product mentioned.

Please send trade news information and illustrations to Sarah Murnal at the BDJ, 64 Wimpole Street, London W1M 8AL.

This issue, the Trade News focus is

Periodontics. Our regular 'what's new' section, for new trade products and services, appears on page 280 .

\section{Don't beat around the Busch}

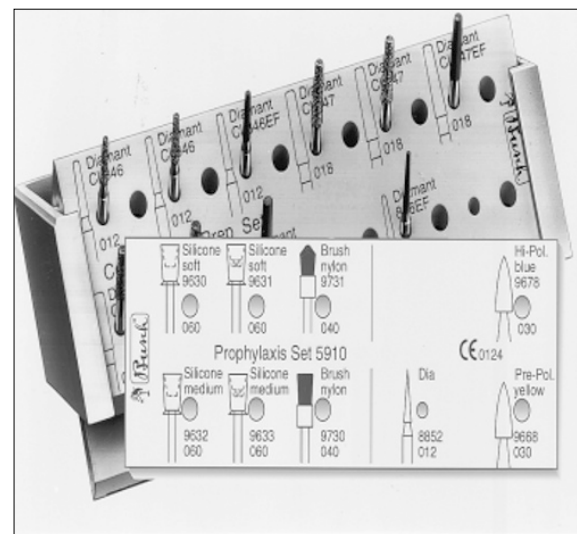

Busch has introduced their prophylaxis and professional scaling/polishing set.

A set of scaling and polishing instruments has been assembled on a STERISAFE bur holder. The set also includes fissure sealing instruments.

The set can be disinfected together with the STERI-SAFE using all common methods. It can be disinfected and cleaned conventionally using immersion disinfection and ultrasonics or automatically in a washer and sterilised by standard autoclaving.

Call Busch on 00492263860 or fax 00 49226320741.

Reader response number:

056

\section{Off the scale!}

The Cavitron SPS Scaler from Dentsply has an autoclavable handpiece which is easily removed for infection control.

The FSI Slimline inserts, used with light pressure, are ideal for subgingival scaling and root planing especially in areas of furcation involvement.

Use of the DualSelect System with chlorhexidine is excellent in the treatment of periodontal pockets. The boost mode helps with tenacious calculus, yet the machine remains quiet. Patient comfort has also improved with the low power setting.

\section{Intelligent filaments}

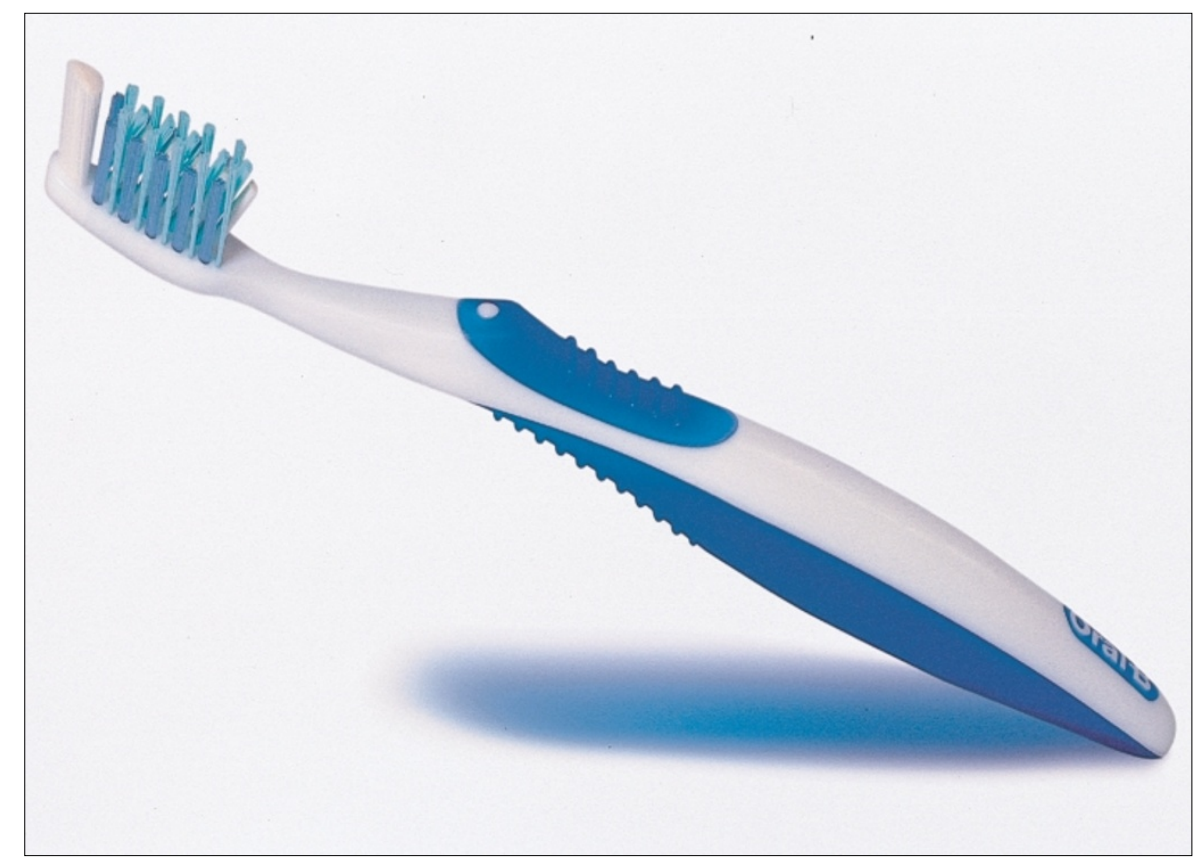

Oral-B have produced a new product they claim will revolutionise toothbrush design - the CrossAction toothbrush.

Research revealed that on average people brush for less than 46 seconds, $75 \%$ of which is dedicated to cleaning posterior teeth. Three different types of brushing motion are used back and forth (65\% of time), up and down (14\%) and circular (21\%) - and there are five basic ways in which a toothbrush is held. These findings were incorporated into the development of the new toothbrush.

Researchers observed how straight filaments tended to skip over the interdental area the most difficult surface to clean. By angling the filaments towards the direction of travel they noticed that the filament would deflect into the interdental space, gaining greater penetration, and would then sweep and lift out plaque. Criss-crossing the filaments would then ensure this action would be achieved with both forward and backward brush strokes.

All of the filaments in CrossAction are therefore angled to gain greater interdental penetration and more prolonged tooth contact.

There are four different sizes and shapes and the handle has been sculpted to provide a secure, comfortable grip whatever the brushing style.

Telephone Michelle Hurd on 01814042306.

Reader response number:

058
Call Sharon Collins on 01932837275.

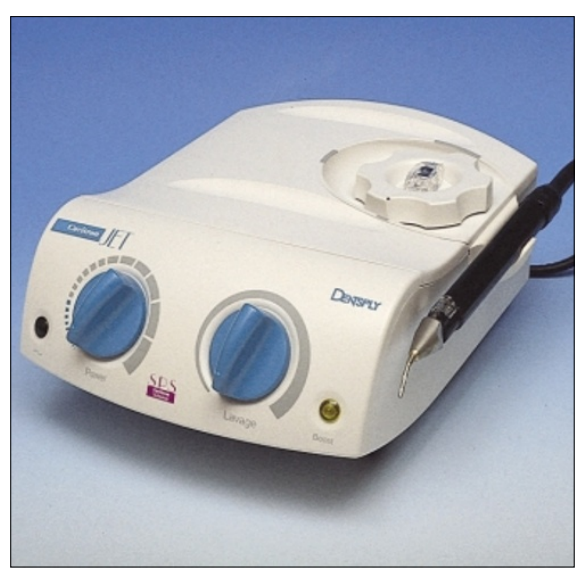

\section{Say so-long to sores}

Ceuta Healthcare claim that Eludril Spray is the only dual action anaesthetic and anti-bacterial formulation on the market. It contains the active ingredients chlorhexidine and amethocaine. These ingredients help reduce the formation of plaque, bacterial and fungicidal loading within the mouth and provide pain relief to affected areas of the mouth and throat.

Eludril Spray can be used to treat:

- Mouth ulcers

- Tonsillitis and pharyngitis

- Oral thrush

Reader response number:

\section{$057 \cdot$ Gingivitis}




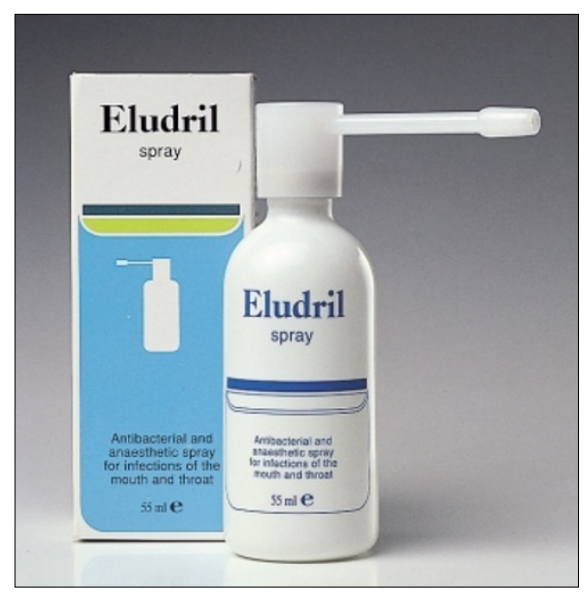

- A.N.U.G

- Other minor conditions of the throat.

Eludril Spray can also be used after operative or dental procedures in the mouth and throat, and for general oral hygiene. It has been designed with a slim, long nozzle to enable treatment of hard to reach spots, such as the back of the throat.

For more information call 01202314824. Reader response number:

059

\section{Terrific tape}

Colgate recently carried out a mailout of Colgate Dental Tape to hygienists and so far, over 300 have responded with very positive results.

Almost 99\% of respondents agreed that the superior gliding action of Colgate Dental Tape improves access even through tight contacts, therefore optimizing plaque removed.

Every hygienist who responded believed Colgate Dental Tape gives greater resistance to shredding or tearing.

Ease of use will often encourage patient compliance. Over $95 \%$ of respondents agreed that the tape would be easier for patients to use, $94 \%$ agreed that it was easy to hold.

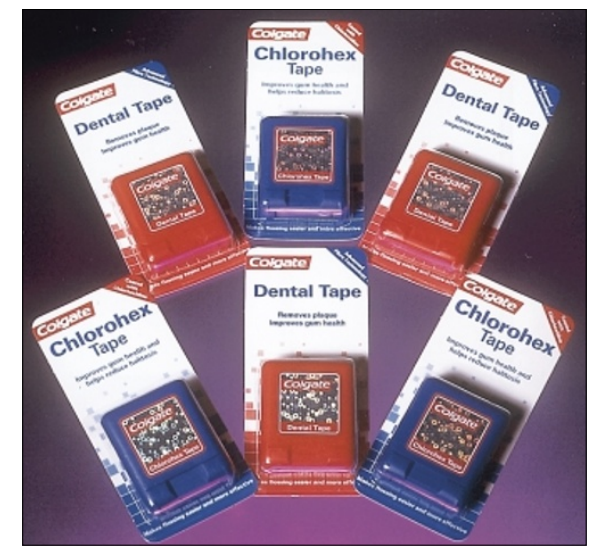

$98 \%$ of hygienists who responded said that they would recommend Colgate Dental Tape to their patients.
For further details telephone 01483401 901 or fax on 01483464444.

Reader response number:

060

\section{Brains and Braun}

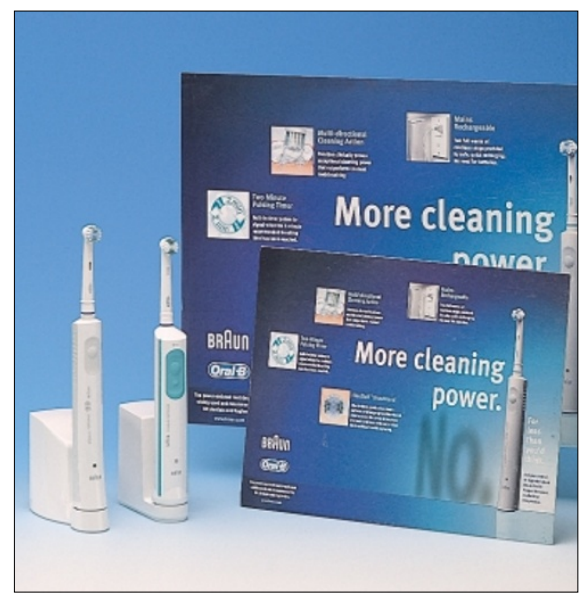

Braun Oral-B's D9 ultra solo electric toothbrush is now available for dentists and hygienists to sell at $\mathfrak{E} 14.99$, which is fifteen pounds less than the RRP. This unit has a two-minute timer function to encourage patient compliance. Also, it does not require batteries.

For further information, please call 0181 4042306.

Reader response number:

061 